\title{
Inkjet-printed flexible RFID antenna for UHF RFID transponders
}

\author{
Grzegorz Tomaszewski*, Piotr Jankowski-MihuŁowicz, MariUsz Węglarski, \\ WOJCIECH LICHOŃ
}

Rzeszow University of Technology, Dept. of Electronic and Communications Systems, al. Powstańców Warszawy 12, 35-959 Rzeszów, Poland

\begin{abstract}
The results of technological investigations in the scope of inkjet-printed flexible RFID antennas dedicated to UHF transponders and also problems with the application of nanomaterials are reported in this paper. The design of the antenna electrical circuit and the parameters of the inkjet printing process were elaborated on the basis of the numerical model prepared in the Mentor Graphics HyperLynx 3D EM software. The project evaluation was performed by measuring electrical parameters of the structures printed with silver-based conductive inks. The obtained results confirm coincidence between the model and its implementation in the inkjet printing technology. Finally, the prepared antenna has been applied in an RFID transponder of $\mathrm{UHF}$ band and the functional tests are also reported in this paper.
\end{abstract}

Keywords: flexible antenna; inkjet printing; RFID transponder; printed electronics

(C) Wroclaw University of Technology.

\section{Introduction}

Investigations in the nanotechnology have fundamental importance for developing contemporary flexible electronics. New nanomaterials such as nanoparticle inks enable printing processes (commonly used in the printing industry) to be used for manufacturing different electronic components [1-3]. Therefore, the inkjet printing technology and aspects of manufacturing some RFID components are the subject of the presented research work $[4,5]$.

Radio Frequency Identification (RFID) is a fast growing technique that is dedicated to contactless identification of various objects. It is applied in different areas of everyday life - in the industry, trade, security and in almost all other socioeconomic spheres - where applied RFID components have to meet various technological, environmental and, above all, low-cost requirements. It is due to the need of integrating RFID transponders with various objects that are characterized by mis-

*E-mail: gtom@prz.edu.pl cellaneous physical properties. Therefore, flexible electronic devices are the most suitable for marking consumer goods, materials and components in production, personal properties, documents, valuables, and many other things. Since a typical RFID passive transponder consists of an antenna and a small chip, the fabrication technology of the RF radiating element is the main barrier to achieve flexibility. The antenna has a relatively large size compared to the chip dimensions and only few technologies can be used for its fabrication. In recent years the inkjet printing techniques are becoming the leading solution in this scope $[6,7]$.

The inkjet printing is a non-contact technology that is used to manufacture low-cost electronics. It consists in additive deposition of functional materials on a substrate (in the near feature it can be a surface of a marked object). The fabrication process is easy and environmentally friendly in comparison with other electronic technologies in which subtractive processes are commonly used. Since the process incorporates few simple steps, the equipment typical of the printing industry can be utilized in a mass production. Because 
of the possibility to reduce the material waste (additive processes) the pollution problems are diminished. Despite the many mentioned advantages, the technological problems associated with resolution, deposition precision and material compatibility have to be overcome [8-10]. Therefore it seems necessary to conduct research works in order to popularize this technology.

\section{Transponder antenna numerical simulation}

The flexible antenna design is considered in the presented research. The elaborated construction is dedicated to the AMS SL900A transponder chip (in the QFN16 package) that operates in the UHF frequency band (860 MHz to $960 \mathrm{MHz}$ ). The geometrical model (Fig. 2a) of the transponder antenna was developed in the Mentor Graphics HyperLynx 3D EM software. The project was worked out for two different substrates: DuPont Kapton HN-500 (PI) (thickness: $125 \mu \mathrm{m}$, relative permittivity: 3.5, loss tangent: 0.0026) and DuPont Mylar (PET) (thickness: $125 \mu \mathrm{m}$, relative permittivity: 2.8, loss tangent: 0.008). The metallic layer of the track pattern was printed by using Harima NPS-J silver nanoparticle ink (assumption: thickness $1 \mu \mathrm{m}$, resistivity $3 \mu \Omega \cdot \mathrm{cm}$ ).

The impedance matching between the transponder antenna and the chip strongly influences the efficiency of wireless power transmission [11]. Therefore the antenna impedance $\mathrm{Z}_{\mathrm{A}}$ has to be complex conjugate of the chip impedance $\mathrm{Z}_{\mathrm{C}}$. So, a numerical model of the antenna that is matched to the previously measured chip impedance $\left(Z_{C}=15\right.$ - j342 $\Omega$ at $866 \mathrm{MHz}$ [12]) has to be prepared before starting the manufacturing process. Since two substrates with different properties are used in the experiment, two modeling studies are considered. In the first case named Free Space Model (FSM), it is assumed that the transponder antenna made from PI material is located on a flat surface in a free space. In the second case named Real Object Model (ROM), it is assumed additionally that the transponder antenna lies on a flat PET surface: this corresponds to the measuring conditions.
The geometrical model parameters are calculated at the assumption of reaching the maximum value of the power transmission coefficient (CMF) for FSM at a frequency that is close to the center of European band $\left(\mathrm{f}_{0}=866 \mathrm{MHz}\right)$ dedicated to RFID systems (according to ETSI EN 302208 standard). The CMF coefficient (Conjugate Match Factor) is defined by equation 1 , where $\mathrm{Z}_{\mathrm{A}}$ and $\mathrm{Z}_{\mathrm{C}}$ are the complex impedances of the antenna and the chip [11, 13]:

$$
C M F=\frac{4 \operatorname{Re}\left(Z_{A}\right) \operatorname{Re}\left(Z_{C}\right)}{\left(\operatorname{Re}\left(Z_{A}+Z_{C}\right)\right)^{2}+\left(\operatorname{Im}\left(Z_{A}+Z_{C}\right)\right)^{2}}
$$

When the $\mathrm{CMF}=1\left(\mathrm{Z}_{\mathrm{A}}=\mathrm{Z}_{\mathrm{C}}^{*}\right)$, the antenna and the chip are ideally matched and entire energy that is harvested by the antenna is transferred to the chip. Such a situation is strongly desired because the read range of the system is the biggest, but it is not achievable in practice.

The structure of the designed antenna (Fig. 1) consists of straight tracks in order to simplify the technological process. Besides the antenna, some parts of the transponder electric circuit are taken into consideration in the numerical model.

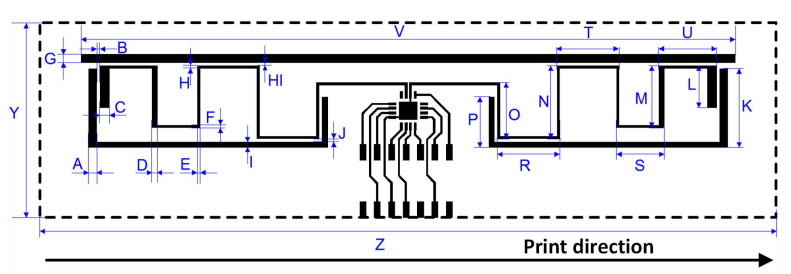

Fig. 1. Geometrical model of transponder antenna.

Selected characteristic dimensions of the transponder construction and the print direction in the technological process are marked in Fig. 1. The project values (PV) and designations (DES) for individual dimensions are shown in the Table 1.

The presented design is a development base for flexible construction of autonomous semipassive transponders dedicated to operating in anticollision dynamic RFID systems. Therefore, it contains additional pads for assembling an extended connector that could be used for attaching an external microcontroller, sensors, energy storage elements, etc. 
Table 1. Dimensions of transponder antenna elements in millimeters.

\begin{tabular}{cccccccccccc}
\hline DES & PV & DES & PV & DES & PV & DES & PV & DES & PV & DES & PV \\
\hline \hline A & 1.50 & E & 0.50 & HI & 0.50 & L & 7.50 & P & 9.00 & U & 10.20 \\
B & 0.50 & F & 0.50 & I & 1.00 & M & 11.00 & R & 11.00 & V & 115.40 \\
C & 1.70 & G & 1.50 & J & 0.50 & N & 13.00 & S & 8.50 & Y & 35.00 \\
D & 1.00 & H & 0.50 & K & 14.00 & O & 10.00 & T & 11.00 & Z & 130.00 \\
\hline
\end{tabular}

\section{Antenna fabrication process}

The antenna fabrication process was carried out in the author's laboratory of integrated electronic micro- and nanotechnology. The transponder antennas (Fig. 2b and Fig. 2c) were realized practically by using the PixDro LP50 ink-jet printing system.
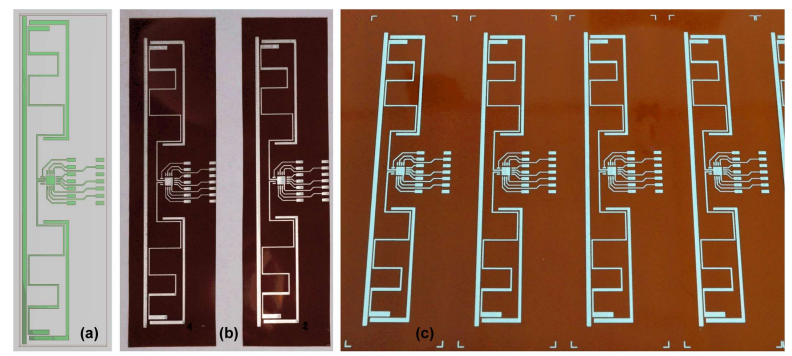

Fig. 2. Transponder antenna: (a) geometrical model, (b) cut samples, (c) samples after printing.

The PI substrate material must be preconditioned before the ink-jet printing process. In the first step, the substrate is washed at $50{ }^{\circ} \mathrm{C}$ in deionized water with $3 \%$ detergent as well as deionized water and next in 2-propanol. In the second step, the substrate is thermally aged at $230{ }^{\circ} \mathrm{C}$ for 60 minutes in order to eliminate shrinkage and stresses during the post-printing sintering.

Before printing, the nanoparticle ink must be warmed up to room temperature in order to obtain suitable rheological parameters. The Spectra SE128 AA piezoelectric print head was used in the experiment. This print head combined of 128 piezoelectric nozzles, 35 microns in diameter, generates about $30 \mathrm{pL}$ drops and is fully compatible with NPS-J ink. The purge and wiping nozzle plate procedures must be performed in order to obtain a stable stream of drops. The stream validation can be accomplished by observing the speed (s) and volume $(\mathrm{V})$ of drops in a print view system. The nozzles $(\mathrm{N})$ selected to the printing process of particular metallic layers, parameters of print head control waveforms (rise/plateau/fall time and pulse amplitude) and results of obtained drop parameters (V and s) are shown in Table 2.

Kapton sheets used as the antenna substrate should be warmed up to the temperature of $60{ }^{\circ} \mathrm{C}$ during the whole printing process in order to prevent excessive and irregular ink spreading. It should be also emphasized that all elements of the printed pattern have to be narrowed down by $80 \mu \mathrm{m}$ on each side in relation to the design model. Subsequent layers of samples (S1 to S7) were printed by one nozzle because the drops generated in the consecutive nozzles had somewhat diversified parameters (volume, speed). Such a kind of printing guaranties stable parameters of drops and in consequence, prevents defects that could appear in the pattern. Nevertheless, such a strategy does not always enable prevention of the excessive ink spreading and this problem has to be eliminated in other ways (by choosing another printing strategy, improving the hydrophobicity of the substrate, decreasing the printing speed, etc.).

The first printout of the sample S1 was printed by N1 nozzle and unfortunately before the next step the drops stopped being generated stable. Therefore, the second layer was made by using another nozzle N11 that was selected in the stream validation procedure. A similar situation occurred in the case of sample S2, where N25 and N47 nozzles were used. The antennas designated as S3 to S7 were printed by the same nozzle N47, because the generated drops were stable during the further manufacturing process. Since the substrate temperature was relatively high, the new printout was performed on the earlier printed semi-dry layer. 
Table 2. Technological parameters used for layers printing.

\begin{tabular}{ccccc}
\hline Sample & S1 & S2 & S3 - S6 & S7 \\
Layer 1 print & N1 & N25 & N47 & N47 \\
Layer 2 print & N11 & N47 & N47 & N47 \\
Layer 3 print & - & - & - & N47 \\
\hline
\end{tabular}

Because of cracks that were revealed during track inspection, only one sample S7 was printed of 3 layers, other, marked as S1 to S6 had 2 layers. All the prints were made with a resolution of $400 \mathrm{dpi}$ and print speed of $300 \mathrm{~mm} / \mathrm{s}$. After the printing processes, the Kapton sheet was placed in a dryer in order to carry out the thermal treatment. The sintering process was conducted at $220{ }^{\circ} \mathrm{C}$ for 60 minutes. Next, the samples were cut out from the Kapton sheet and measured. In the last stage the Elpox AX-15S silver conductive adhesive was used to mount the AMS SL900A transponder chip. The glued samples were dried at $60{ }^{\circ} \mathrm{C}$ for 120 minutes in order to reduce the stresses.

\section{Problem of nanomaterial appli- cation}

Despite the fact that inkjet printing processes are relatively simple techniques to fabricate flexible electronics, there are some problems connected with nanoparticle ink deposition and functionalization of deposited layers. In the source literature on the micro- and nanotechnology, the mentioned problems are very rarely exposed in the application context. Therefore in this section of the paper, some aspects connected with investigations into material deposition processes are described.

The application of nanomaterials for fabrication of flexible electronic devices in the inkjet printing processes is more complicated than it is in the traditional printing industry, because properties of nanoparticle solutions are different form common inks. Generally, inks are dosed by printing heads with piezoelectric nozzles. The shape, volume and velocity of the drops are formed by electrical impulses that power piezoelectric elements. But the real parameters of the drop are dependent on many other environmental properties. When paintings are

$$
\begin{aligned}
& \mathrm{N} 1-5 / 14 / 7 \mu \mathrm{s} 77 \mathrm{~V} \rightarrow \mathrm{V}=30.1 \mathrm{pL} ; \mathrm{s}=1.9 \mathrm{~m} / \mathrm{s} \\
& \mathrm{N} 11-5 / 14 / 7 \mu \mathrm{s} 77 \mathrm{~V} \rightarrow \mathrm{V}=22.2 \mathrm{pL} ; \mathrm{s}=2.2 \mathrm{~m} / \mathrm{s} \\
& \mathrm{N} 25-5 / 14 / 7 \mu \mathrm{s} 77 \mathrm{~V} \rightarrow \mathrm{V}=33.1 \mathrm{pL} ; \mathrm{s}=1.5 \mathrm{~m} / \mathrm{s} \\
& \mathrm{N} 47-7 / 8 / 11 \mu \mathrm{s} 77 \mathrm{~V} \rightarrow \mathrm{V}=39.2 \mathrm{pL} ; \mathrm{s}=2.2 \mathrm{~m} / \mathrm{s}
\end{aligned}
$$

printed on paper, the process inadequacy are imperceptible to the human eye. The situation is different in the case of functional materials. The inaccuracies of the ink-jet process affect the parameters of a target electronic structure. In practice, when all nozzles of a printing head are powered by the same impulses, the obtained streams of drops may vary so much that it is not possible to unequivocally define the quality of printed structure. Moreover, the parameters of drops change over time of a single process. The reason of such a situation is difficult to explain, but in the source literature, nozzle clogging effects caused by agglomeration of nanoparticles in conductive inks and heating of substrate are often indicated [14].

The designed pattern is transferred effectively on a flexible substrate by the drop-on-demand inkjet printing method only when the stream of drops is stable. In order to obtain a good print quality, the ejected drop cannot have a long tail (Fig. 3a) and satellites (Fig. 3b). The situation would be the best if the ejected stream was stable and equal for all nozzles of the print-head. Unfortunately, in the practice this scenario is impossible because the drops generated by different nozzles have different velocity (speed, velocity vector) (Fig. 3c) and volume, even at the same parameters of the powered impulses. Any deviations of the drop stream from the vertical direction (relative to the substrate) are very undesirable as they cause defects in the electronic structure (Fig. 3d). The best streaming is when the vector of drop velocity is perpendicular to the substrate (Fig. 3e).

In some cases, results of the mentioned problems are visible but they do not exclude the electronic structure from the later use (Fig. 3f). However, in many cases, especially when a lot of printing nozzles are used, the probability of the defect appearance (caused by drop displacement) is so 


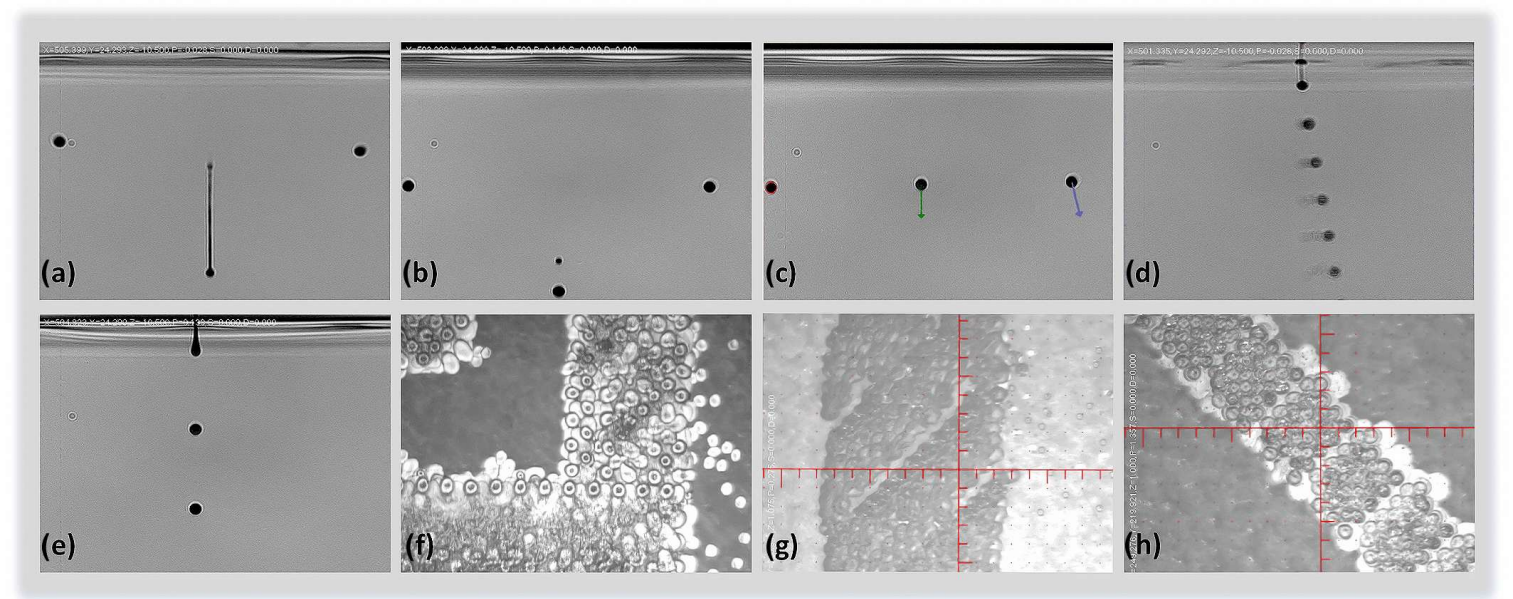

Fig. 3. Nanomaterial deposition problems: $(\mathrm{a}-\mathrm{e})$ different parameters of generated drops, $(\mathrm{f}-\mathrm{h})$ structure defects.

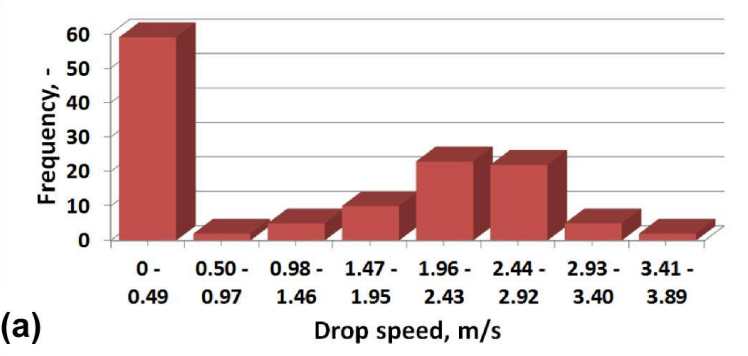

(a)

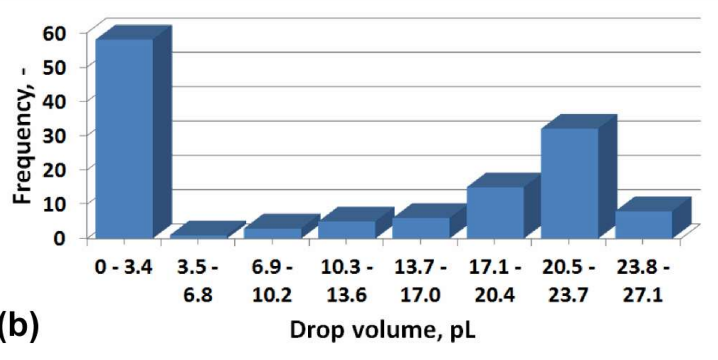

(b)

Fig. 4. Printhead drops frequency distribution for: a) given speed, b) given volume.

high (Fig. 3g and Fig. 3h) that obtained parameters definitely do not meet the requirements of the target application (too high resistance or discontinuity of paths).

The problems of uniform drop generation for SE-128 AA printhead and nanoparticle ink are partly shown in Fig. 4.

The test was performed with a printhead used for the fifth time in the technological process. All nozzles of the printhead were studied at 5/14/7 $\mu \mathrm{s}$ for the pulse time parameters and $77 \mathrm{~V}$ for amplitude of fire pulse as well $1 \mathrm{kHz}$ for operating frequency. The frequency distribution of drop speed (Fig. 4a) and drop volume (Fig. 4b) for all piezoelectric nozzles were determined. As it can be seen on the graphs, the diversification between the parameters of generated drops is huge, but in practice only a few nozzles generate stable perpendicular streams (Fig. 3e) that ensure the effective deposition process. Moreover, in the long period of technological process, the distribution can undergo slight changes, therefore realization of the process with many nozzles is difficult.

The spread of ink is another problem connected with the ink rheological parameters, substrate surface properties and drop volume (Fig. 5). The prediction of this phenomena is crucial for effective application of nanoparticle material, but it is very difficult and depends on the properties of used material.

Therefore substrate materials often have to be pre-treated before printing processes or process parameters such as substrate temperature, print resolution, print speed etc. have to be adjusted.

The first problematic issue in spreading ink on an untreated and unheated polyimide substrate are irregular edges of the paths (Fig. 5a). Significant deviation from the pattern definitely excludes 


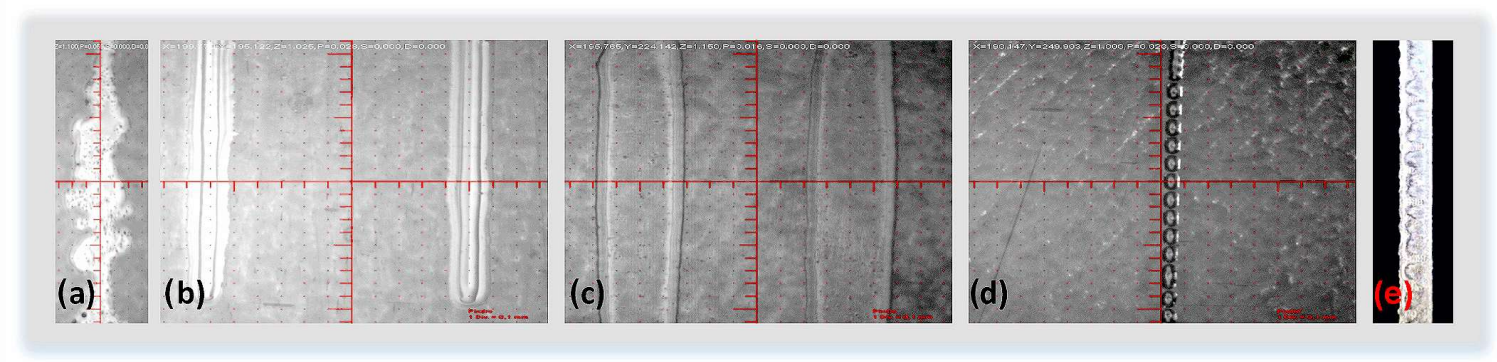

Fig. 5. Ink spreading problems: (a) lack of regularity, (b) various conditions of wettability, (c) strongly hydrophilic substrate, (d) strongly hydrophobic substrate, (e) heterogeneity in the spread.

printed structures from the later use, especially in RF application. Moreover, in this case the prediction of structure shapes is impossible. The situation is considerably improved when the substrate is heated (Fig. 5b to Fig. 5e) to $60{ }^{\circ} \mathrm{C}$. The quality of the spreading with the same ink clearly depends on substrate surface properties. However, the line formed by a single $30 \mathrm{pL}$ droplets printed with resolution of $400 \mathrm{dpi}$ is relatively wide on the polyimide substrate that is slightly treated with $\mathrm{KOH}$ solution and it reaches up to $200 \mu \mathrm{m}$ in the first layer (Fig. 5b). The second layer printed on the first one is sharper and it is $100 \mu \mathrm{m}$ wide. The best wettability occurs on the plasma treated polyimide film and the line reaches up to $400 \mu \mathrm{m}$ (Fig. 5c). It promotes a good adhesion but significantly limits the smallest dimension of printed structures. An opposite situation occurs on the polyimide surface coated with a thin hydrophobic layer, but the spread is so little that the line is not continuous (Fig. 5d). The last mentioned application problem observed on the polyethylene terephthalate (PET) substrate is related with defects on one of printed layer (Fig. 5e) where heterogeneity in the spreading causes the increase of sheet resistance of silver layer.

\section{Geometric and electrical results of printed structures}

The morphology of the printed structures (Fig. 6) was observed by the Pixdro Printview System and Dino-Lite digital microscope. The line width created from drops ejected by the single nozzle (N1) on the heated substrate (resolution of
$400 \mathrm{dpi}$ ) is about $100 \mu \mathrm{m}$ (Fig. 6a). Similar dimension is observed for the second layer created by the same nozzle (Fig. 6b). Surface energy of the Kapton material is approximately $38 \mathrm{mN} / \mathrm{m}$ (measured with test ink). Therefore the ink does not spread excessively and the lines have regular shapes.

The sintered structures (Fig. 6c to Fig. 6j) very often have little defects in various forms. A lot of transponder circuit elements have irregular edges (Fig. 6c to Fig. 6f). In most analyzed cases, some details of the printouts are wider than the modeled structures but mostly no more than $150 \mu \mathrm{m}$ (rarely encountered maximal differences do not exceed $200 \mu \mathrm{m}$ width, Fig. 6h). Local decrements of dimensions much more rarely appear and have no more than $120 \mu \mathrm{m}$. The blank subarea metal layer (on the path labeled with the dimension I in Fig. 1) is visible only in one case S3 (Fig. 6g). The defect is caused by local strong hydrophobic nature of the substrate surface. The spread disturbances also appear in several other cases in which the surface of substrate material is locally more hydrophilic: it can be noticed in the first printed layer (Fig. 6f). In addition, longitudinal flaws are observable on some elements of the 2-layer structures (Fig. 6h) and very big cracks and flaking of metallic coating (Fig. 6i and Fig. 6j) on large planes of the 3-layer structures (S7). It should be noticed on the basis of comparison of 2- (Fig. 6e) and 3- (Fig. 6j) layer samples that the flaking appears particularly on large surfaces of the 3-layer printouts. Therefore it can be concluded that the threefold printing is not effective. Based on a simple morphology analysis it can be also seen that the space between the elements 

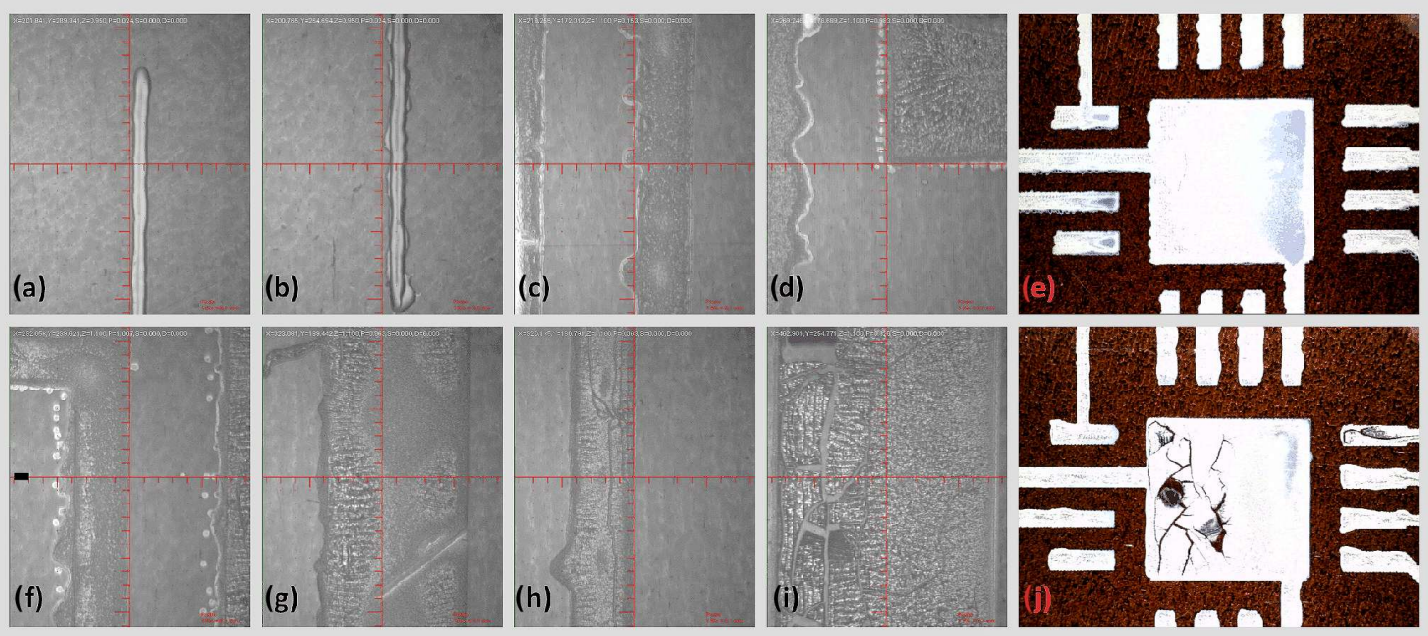

(f)

(g)

(h)

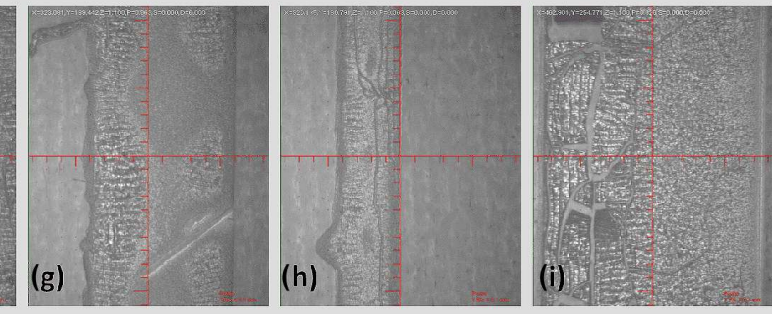

Nanosilver ink on polyimide substrate

Fig. 6. Morphology of printed structures.

as well as elements width should be wider than $200 \mu \mathrm{m}$ in order to obtain effective pattern transfer at the used technological parameters.

Thorough geometry analysis of the representative samples (S1, S3 and S7) is possible on the basis of data presented in the Table 3. Designations in Table 3 correspond to the designations in Table 1 and Fig. 1.

The real values of dimensions (RV) are calculated as the arithmetic mean from 20 measurements of selected elements for the each investigated antenna. It can be seen that some dimensions increase $(+\Delta \mathrm{RV})$ and other decrease $(-\Delta \mathrm{RV})$ with regard to the model described in Table 1. The difference $\Delta \mathrm{RV}$ between RV and PV does not exceed $140 \mu \mathrm{m}$ for the element width and $190 \mu \mathrm{m}$ for the gap. The minimal $\left(\mathrm{RV}_{\mathrm{MIN}}\right)$ and maximal $\left(\mathrm{RV}_{\mathrm{MAX}}\right)$ values indicate that the width of some inkjet printed paths changes up to $190 \mu \mathrm{m}$ in comparison to the average value $R V$.

The electrical measurements of the tested structures were carried out in the author's RFID laboratory using a two-port vector network analyzer (VNA) and a differential probe (Fig. 7b).

The transponder antenna parameters of the prepared samples S1 to S7 were confirmed by measuring S-parameters. The experiments were carried out by using the VNA Agilent PNA-X N5242A and the passive differential probe connected with a micromanipulator (Model 44-D) that was attached to a XYZ positioner (model: $110 / 210$, resolution: $2.2 \mu \mathrm{m}$, max. travel in each axis: $10 \mathrm{~mm}$ ). This equipment was connected by flexible test cables: Agilent 85131F and Huber+Suhner (Astrolab) minibend. After calibration of the test stand the $S$ parameters were measured and the results were used in the impedance parameter calculations according to [15]. The calculations were performed for each sample by using equation 2 , where the wave impedance $Z_{0}=50 \Omega$ :

$$
Z_{A}=2 Z_{0} \frac{S_{12}^{2}-S_{11}^{2}-2 S_{12}+1}{\left(1-S_{11}\right)^{2}-S_{12}^{2}}
$$

The measured and calculated antenna circuit parameters for the operating frequency $\mathrm{f}_{0}=866 \mathrm{MHz}$ are summarized in the Table 4.

Relatively small differences between the measured parameters can be observed. In each case the real part of the antenna impedance is higher than in the numerical model. The defects that appear on the printed elements are the main reason of the resistance increase. Both the cracks and the shape change of some conductive paths lead to the substantial resistance increase. Moreover, some elements have locally printed defects connected with 
Table 3. Dimensions of realized transponder antenna elements in millimeters.

\begin{tabular}{ccccccccccccc}
\hline & & $\mathrm{RV}$ & \multicolumn{3}{c}{$\Delta \mathrm{RV}$} & \multicolumn{3}{c}{$\mathrm{RV}_{\mathrm{MIN}}$} & \multicolumn{3}{c}{$\mathrm{RV}_{\mathrm{MAX}}$} \\
$\mathrm{DES}$ & $\mathrm{S} 1$ & $\mathrm{~S} 3$ & $\mathrm{~S} 7$ & $\mathrm{~S} 1$ & $\mathrm{~S} 3$ & $\mathrm{~S} 7$ & $\mathrm{~S} 1$ & $\mathrm{~S} 3$ & $\mathrm{~S} 7$ & $\mathrm{~S} 1$ & $\mathrm{~S} 3$ & $\mathrm{~S} 7$ \\
\hline \hline $\mathrm{A}$ & 1.60 & 1.52 & 1.50 & 0.10 & 0.02 & 0.00 & 1.58 & 1.50 & 1.50 & 1.65 & 1.55 & 1.55 \\
$\mathrm{C}$ & 1.84 & 1.76 & 1.80 & 0.14 & 0.06 & 0.10 & 1.75 & 1.70 & 1.78 & 1.90 & 1.85 & 1.82 \\
$\mathrm{D}$ & 1.10 & 1.00 & 1.00 & 0.10 & 0.00 & 0.00 & 1.05 & 1.00 & 1.00 & 1.15 & 1.10 & 1.10 \\
$\mathrm{E}$ & 0.48 & 0.42 & 0.42 & 0.02 & -0.08 & -0.09 & 0.40 & 0.38 & 0.38 & 0.60 & 0.48 & 0.47 \\
$\underline{\mathrm{F}}$ & 0.47 & 0.43 & 0.45 & -0.03 & -0.07 & -0.05 & 0.40 & 0.38 & 0.40 & 0.52 & 0.52 & 0.52 \\
$\underline{\mathrm{G}}$ & 1.64 & 1.60 & 1.63 & 0.14 & 0.10 & 0.13 & 1.55 & 1.58 & 1.60 & 1.70 & 1.61 & 1.65 \\
$\underline{\mathrm{H}}$ & 0.45 & 0.40 & 0.40 & -0.06 & -0.10 & -0.10 & 0.36 & 0.38 & 0.39 & 0.50 & 0.53 & 0.50 \\
$\underline{\mathrm{HI}}$ & 0.64 & 0.65 & 0.69 & 0.14 & 0.15 & 0.19 & 0.62 & 0.55 & 0.67 & 0.65 & 0.68 & 0.70 \\
$\underline{\mathrm{I}}$ & 1.06 & 1.03 & 1.01 & 0.06 & 0.03 & 0.01 & 1.00 & 1.00 & 1.00 & 1.10 & 1.20 & 1.20 \\
$\mathrm{~V}$ & 115.30 & 115.25 & 115.29 & -0.10 & -0.15 & -0.11 & underlined - cross dimension to print direction \\
\hline
\end{tabular}

Table 4. Parameters of the transponder antenna.

\begin{tabular}{cccccccccc}
\hline & FSM & ROM & S1 & S2 & S3 & S4 & S5 & S6 & S7 \\
\hline \hline $\operatorname{Re}(Z), \Omega$ & 37 & 51 & 129 & 130 & 114 & 113 & 115 & 110 & 107 \\
$\operatorname{Im}(Z), \Omega$ & 336 & 479 & 433 & 455 & 440 & 447 & 447 & 431 & 449 \\
$\mathrm{CMF},-$ & 0.81 & 0.13 & 0.26 & 0.23 & 0.26 & 0.24 & 0.24 & 0.28 & 0.24 \\
\hline
\end{tabular}

worsened wetting conditions of the substrate material. The increase of the resistance can be also observed in the self-resonance frequency (Fig. 7a). It can also be seen that the increase of the conductive track thickness achieved by printing of more layers (S7) does not lead to significant resistance decrease, so, since there is a great probability that the defects appearance destroys the 3-layer sample (Fig. 6i and Fig. 6j), it is not efficient to manufacture antennas in this way. The small influence of the technological process parameters on the antenna resistance can also be observed. The change of the printing nozzles leads to the changes of drop parameters. The samples S1 and S2 have clearly higher resistance than the others. Small changes of the layer thickness caused by variation in the drop volume (Table 2) are the reason of the mentioned difference. Therefore, the samples S3 to S7 printed with drops of higher volume are thicker and consequently have the lower resistance (Table 4).

The numerical simulations confirm that both the changes of the material parameters as well as the geometry of the printed conductive layers have significant impact on the antenna impedance. Since it is impossible to provide ideal environmental conditions during the tests, the main FSM model has to be adjusted to the real state of the experiment. The material parameters of the measured substrate considered in the research have been taken into account in the new ROM model. As it can be seen in Fig. 8, the impedance of the transponder antenna changes, especially its imaginary part. It can also be observed that a small difference in the imaginary part of the measured impedance appears for each sample. These differences are a result of the changes in the geometry of printed elements. The CMF coefficient of measured samples does not reach the model values (Fig. 7a), but obtained results are satisfactory.

\section{Application test results}

The constructions of the flexible transponder antenna were tested in an anechoic chamber in the Laboratory of Electromagnetic Compatibility. The samples with mounted chips were integrated with a PET bottle (Fig. 9a) and a cardboard box (Fig. 9b). The radius of the used bottle was $42.5 \mathrm{~mm}$, therefore the transponder antenna had to be flexed. 


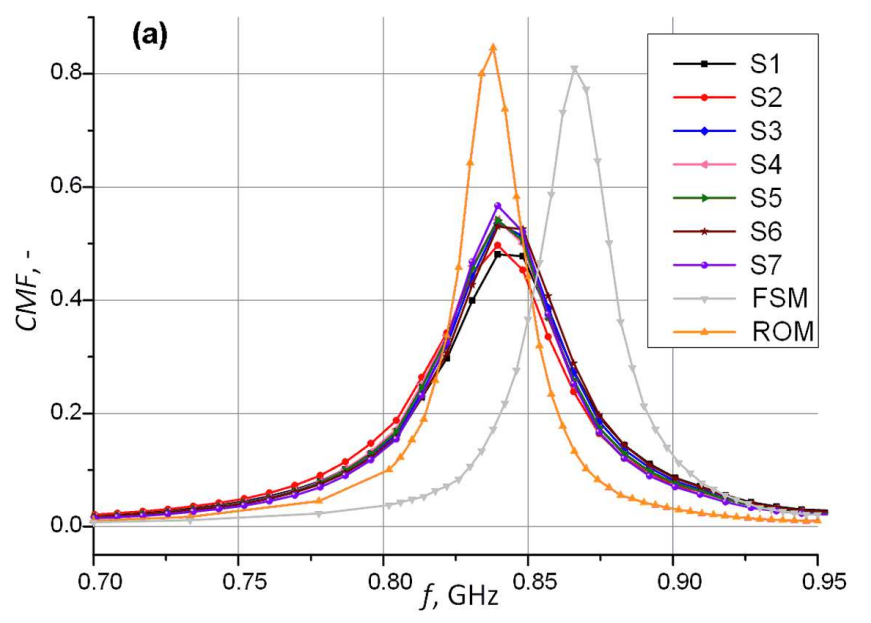

(b)

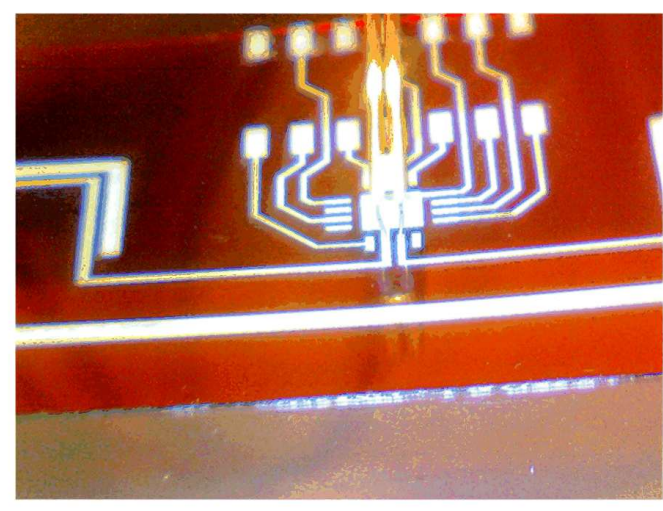

Fig. 7. Transponder antenna parameters: (a) CMF, (b) a sample under the test.
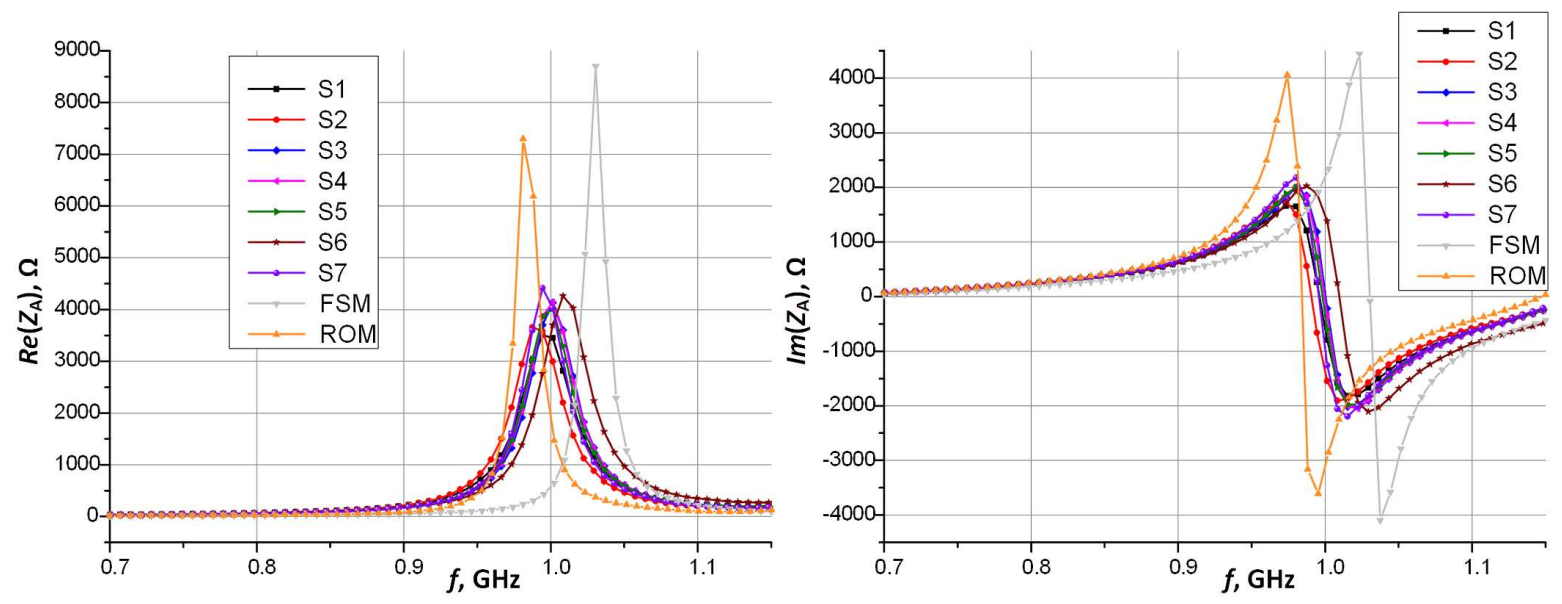

Fig. 8. Impedance of transponder antenna: $\operatorname{Re}\left(\mathrm{Z}_{\mathrm{A}}\right)$ - real part, $\operatorname{Im}\left(\mathrm{Z}_{\mathrm{A}}\right)$ - imaginary part.

The real communication process was carried out between the read/write device (RWD) (ID ISC.LRU2000) and tested transponders located in the symmetry axis of the RWD antenna (ID ISC.ANTU250/250). The transponders were tested by sending the command Query at different values of the output power level ( $\mathrm{P}_{\text {OUT }}$ ) set in the read/write device. The maximal distance $\mathrm{R}_{\max }$ (read range) between the RFID chip and the RWD antenna was determined (Table 5) for three values of POUT.

The transponder was oriented horizontally on the bottle (index $\mathrm{PH}$ ) and the box (index $\mathrm{BH}$ ) and additionally vertically on the box (index BV). The correctness of the identification was confirmed by 100 Query commands sent one by one at a time interval of $500 \mathrm{~ms}$. As it can be seen, the maximum distance reaches 21 centimeters but both of the orientation and the object properties with which transponder is integrated affect its functionality.

Table 5. Maximal distance (read range) for tested transponders in centimeters.

\begin{tabular}{cccc}
\hline $\begin{array}{c}\text { Pout } \\
\text { [W] }\end{array}$ & $\begin{array}{c}\mathrm{R}_{\mathrm{PH} \max } \\
{[\mathrm{cm}]}\end{array}$ & $\begin{array}{c}\mathrm{R}_{\mathrm{BHmax}} \\
{[\mathrm{cm}]}\end{array}$ & $\begin{array}{c}\mathrm{R}_{\mathrm{BVmax}} \\
{[\mathrm{cm}]}\end{array}$ \\
\hline \hline 2.0 & 13 & 19 & 21 \\
1.5 & 12 & 17 & 19 \\
1.0 & 11 & 11 & 15 \\
\hline
\end{tabular}




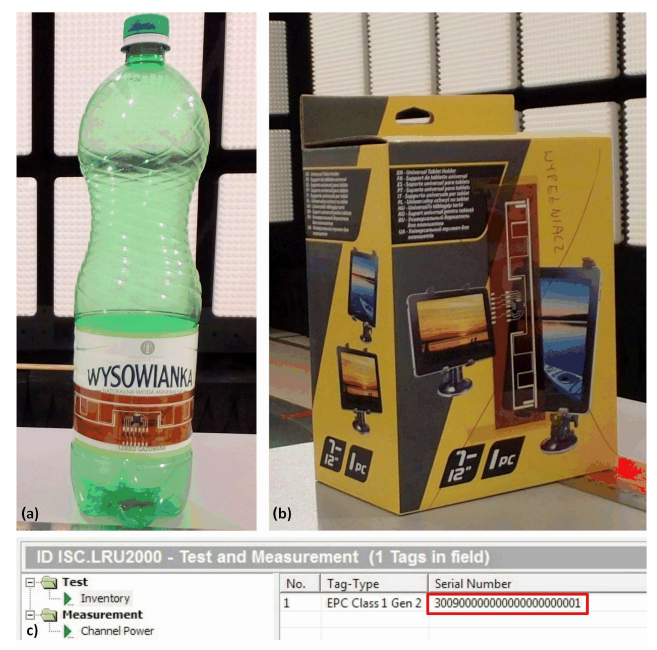

Fig. 9. Transponders under application tests: (a) integration with a PET bottle, (b) integration with a cardboard box, (c) record of the serial number in the RWD application.

\section{Conclusion}

The process of flexible antenna fabrication, validation study of the UHF RFID transponder and application problems of using nanomaterials are presented in this paper. The main focus is placed on the manufacturing of the flexible RFID antenna in the inkjet printing technology. The whole transponder fabrication process is described in details. The antennas have been practically realized in the author's laboratories equipped with sophisticated technology devices and their parameters have been measured in the RFID and EMC laboratory with using special measuring apparatus. The analysis of the antenna geometry obtained in the inkjet printing process is provided by the authors. The characteristics of used materials and process parameters are taken into account in the investigations. The obtained results of measurements and calculations are also compared. The validity of the realized antenna structures is confirmed by the practical application tests with real marked objects. The tested structures operate properly in the RFID system so both, application of nanomaterial inks as well as the use of inkjet printing technology lead to achieving the established purpose.

\section{Acknowledgements}

This work was supported in part by the Polish National Centre for Research and Development (NCBR) under Grant No. PBS1/A3/3/2012. The work was developed by using the equipment purchased in the Operational Program Development of Eastern Poland 2007 - 2013 of the Priority Axis I Modern Economics of Activity I.3 Supporting Innovation under Grant No. POPW.01.03.00-18-012/09-00 and the Program of Development of Podkarpacie Province of The European Regional Development Fund under Grant No. UDARPPK.01.03.00-18-003/10-00.

\section{References}

[1] Felba J., Schaefer H., Materials and Technology for Conductive Microstructures, in: MORRIS J.E. (Ed.), Nanopackaging: Nanotechnologies and Electronics Packaging, Springer, Boston, 2008, p. 239.

[2] Shen W., Zhang X., Huang Q., Xu Q., Song W., Nanoscale, 6 (3) (2014), 1622.

[3] JaKubowska M., Techniki drukarskie $w$ elektronice. Materiaty $i$ technologie (Printing Techniques in Electronics. Materials and Technologies), Oficyna Wydawnicza Politechniki Warszawskiej, Warszawa, 2013.

[4] Tarapata G., Paczesny D., Kawecki K., SPIE, 8903 (89032I) (2013), 1.

[5] Jankowski-MinuŁowicz P., Tomaszewski G., WęGlarski M., Przeglad Elektrotechniczny, 4 (2015), 1.

[6] Ortego I., Sanchez N., Garcia J., Casado F., Valderas D., Sancho J.I., Int. J. Antenn. Propag., 2012 (2012), 1.

[7] Koski K., Koski E., Virtanen J., Buörninen T., SyDÄNHEIMO L., UKKONEN L., ElSHERBENI A., Int. J. Adv. Manuf. Tech., 62 (2012), 167.

[8] LiM Y.Y., GoH Y.M., LiU C., Ind. Eng. Chem. Res., 52 (2013), 11564.

[9] Derby B., J. Eur. Ceram. Soc., 31 (2011), 2543.

[10] Tomaszewski G., Potencki J., WaŁach T., PILECKI M., Elektronika, 3 (2015), 25.

[11] Grosinger J., Scholtz Ove A., E\&I, 128 (11 - 12) (2011), 408.

[12] Jankowski-MinuŁowicz P., Węglarski M., Electron. Electr. Eng., 20 (9) (2014), 65.

[13] Jankowski-MinuŁowicz P., Lichoń W., PitERA G., WęGLARSKI M., Elektronika, 1 (2014), 41.

[14] Yin Z., Huang Y., Bu N., Wang X., Xiong Y., Chinese Sci. Bull., 55 (2010), 3383.

[15] Jankowski-MinuŁowicz P., Pitera G., Węglarski M., Metrol. Meas. Syst., 3 (2014), 509.

Received 2016-02-01 Accepted 2016-08-25 